\title{
Subkostal Kesi Fıtığı Onarımında Yama Sabitlemede Sütür Kullanımı: Olgu Sunumu
}

\author{
Mesh Fixation with Sutures in Subcostal Incisional Hernia: A Case Report
}

\author{
Yalın İŞCAN ${ }^{1}$, Birol AĞCA ${ }^{1}$, Aziz Bora KARİP ${ }^{1}$, Ender ONUR ${ }^{1}$, Kemal MEMIŞOĞLU ${ }^{1}$ \\ 1. Fatih Sultan Mehmet Eğitim Ve Araşttrma Hastanesi Genel Cerrahi Ünitesi, İstanbul
}

\section{$\ddot{O Z Z E T}$}

Kesi fitıklarında laparoskopi siklikla kullanılmaktadır. Zımba atıcılar sayesinde yama sabitleme oldukça kolaylaşmıştır fakat bu aletlerin subkostal bölgede etkinliği azalmaktadır. Transfasyal dikişler, zımba atıcılar için açısı zor ve riskli bölgelerde alternatif olarak kullanilabilirler.

Anahtar Kelimeler: transfasyal sütür, kesi fitığı, laparoskopik fitık tamiri

\section{ABSTRACT}

Aim: Laparoscopy is often performed in incisional hernia. Mesh fixation became easier with staples but the effectiveness of these instruments reduced in subcostal region. Transfacial sutures are alternatives for staples in difficult and risky places.

Keywords: transfacial sutures, incisional hernia, laparoscopic hernia repair

\section{GİRIŞ}

Her on laparotominin birinden kesi fitığ 1 gelişmektedir (1). Kesi fitığı onarımı tüm dünyada oldukça sık uygulanan ameliyatlardan biridir (2). Onarım, hem açık hem de laparoskopik olarak yapılabilir. Laparoskopik ameliyatın güvenilirliği, açık yöntemler ile eştir (3-6). Laparoskopide yama sabitleme zımba atıcılar ve transfasyal dikişler ile yapılmaktadır (5). Yama sabitleyiciler ameliyat süresini oldukça kısaltmakla beraber, sinir zedelenmesine bağlı kronik ağrılara sebep olabilmektedirler. Bu çalışmada, yama sabitleyiciye alternatif olarak, transfasyal dikiş tekniğinin, torakoabdominal bölge kesi fitığı onarımında, etkin olduğunu gösteren bir olguyu sunmayı amaçladık.

\section{OLGU SUNUMU}

Safra kesesi taşı tanısı ile iki yıl önce açık kolesistektomi yapılan 52 yaşında kadın hastada, ameliyattan 2 ay sonra kesi fitığı saptanmış. Hikayesinde, daha önce iki defa önden yaklaşımla prolen yama onarımı olan hastada, fizik muayenede sağ üst kadranda yaklaşık $25 \times 10 \mathrm{~cm}$ fasya defekti palpe edilmekteydi, muayenede ele fasyadan ayrılmış prolen mesh gelmekteydi. Bilgisayarlı tomografide sağ üst kadranda fasya defekti, bu defektten protrüze olmuş ve sağda toraks duvarı ile cilt arasında uzanan bağırsak ansları saptanmıştı (Resim 1).

Ameliyatta sol üst kadrandan açık yöntemle girilen $10 \mathrm{~mm}$ port ile pnömoperiton oluşturuldu. Sağ alt kadrana $5 \mathrm{~mm}$ ve sol alt kadrana $10 \mathrm{~mm}$ çalışma portu yerleştirildi. Fıtık içeriği keskin diseksiyonla batına iade edildi. Fitık defekti net olarak izlenip karından alınan izdüşümüyle yamanın ölçüleri hesapland1 (Resim 2). Yapışıklık önleyici yama uygun ölçüde kesilip dört köşesine 2/0 polipropilen tespit sütürleri atıldı ve karın içine gönderildi. Sütür tutucu yardımıyla yama karın duvarına asıldı ve kot kavsine uzak tarafi emilebilir sabitleyicilerle, karın duvarına sabitlendi. Suprahepatik-alt torakal bölgede, uygun zımbalama açısı sağlanamaması ve ameliyat sonrası olası kronik ağriyı engellemek için, zımba ile tespit yapılmadı. $15 \mathrm{~cm}$ uzunluğunda kesilmiş 2-0 poliprolen 8 adet sütür parçası karın içerisine alındı ve karaciğer üstüne konuldu.

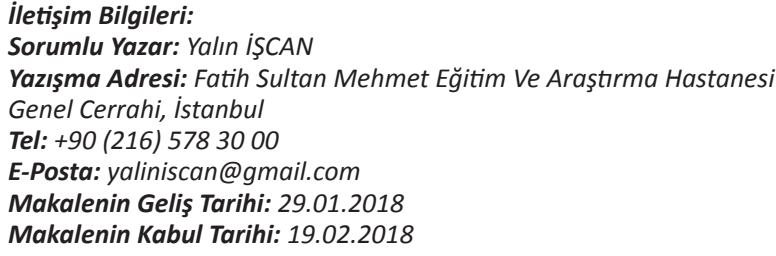




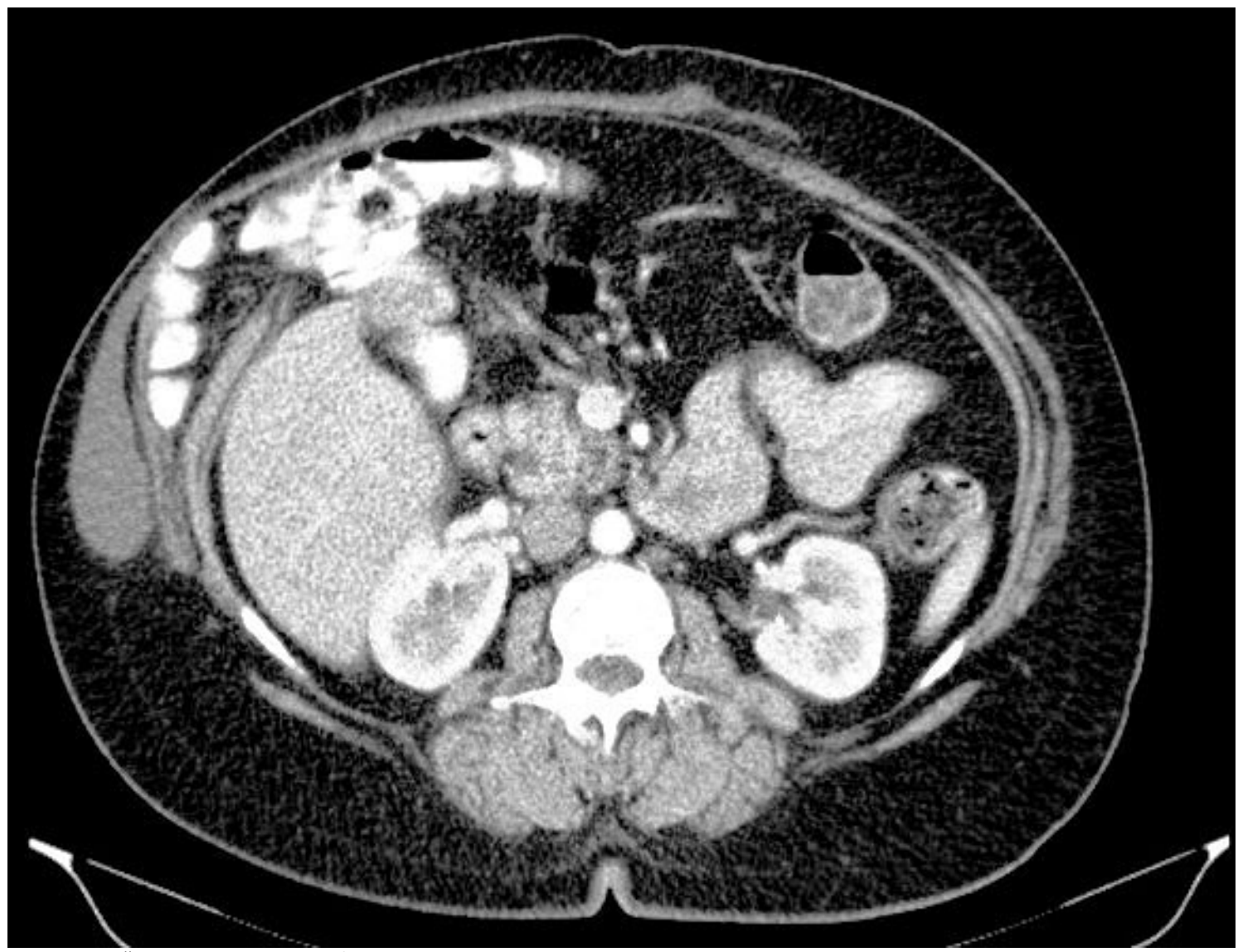

Resim 1. Fıtı̆ıı bilgisayarlı tomografi görünümü.

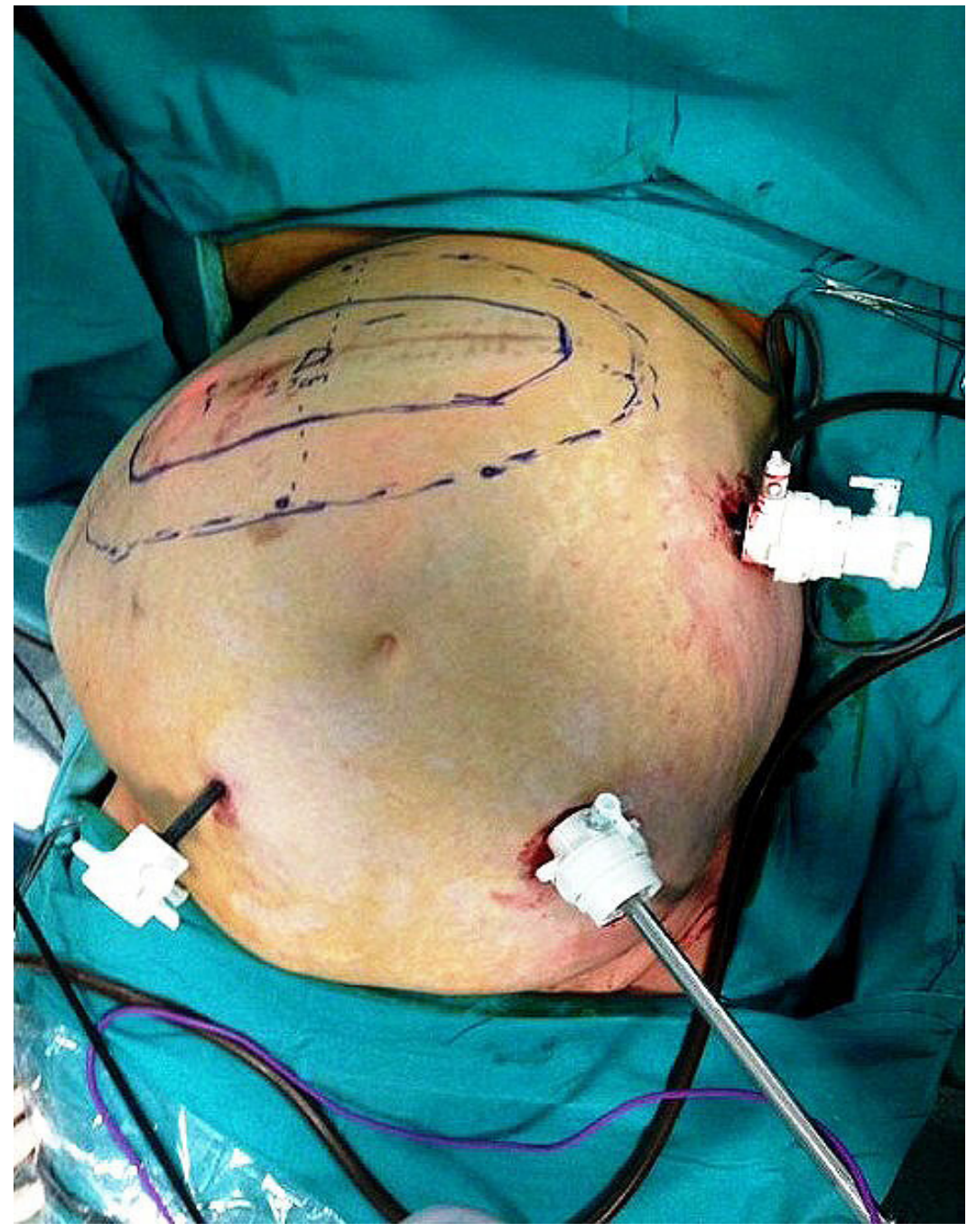

Resim 2. Trokar girişleri ve fittk defektinin cilde izdüşümü. 


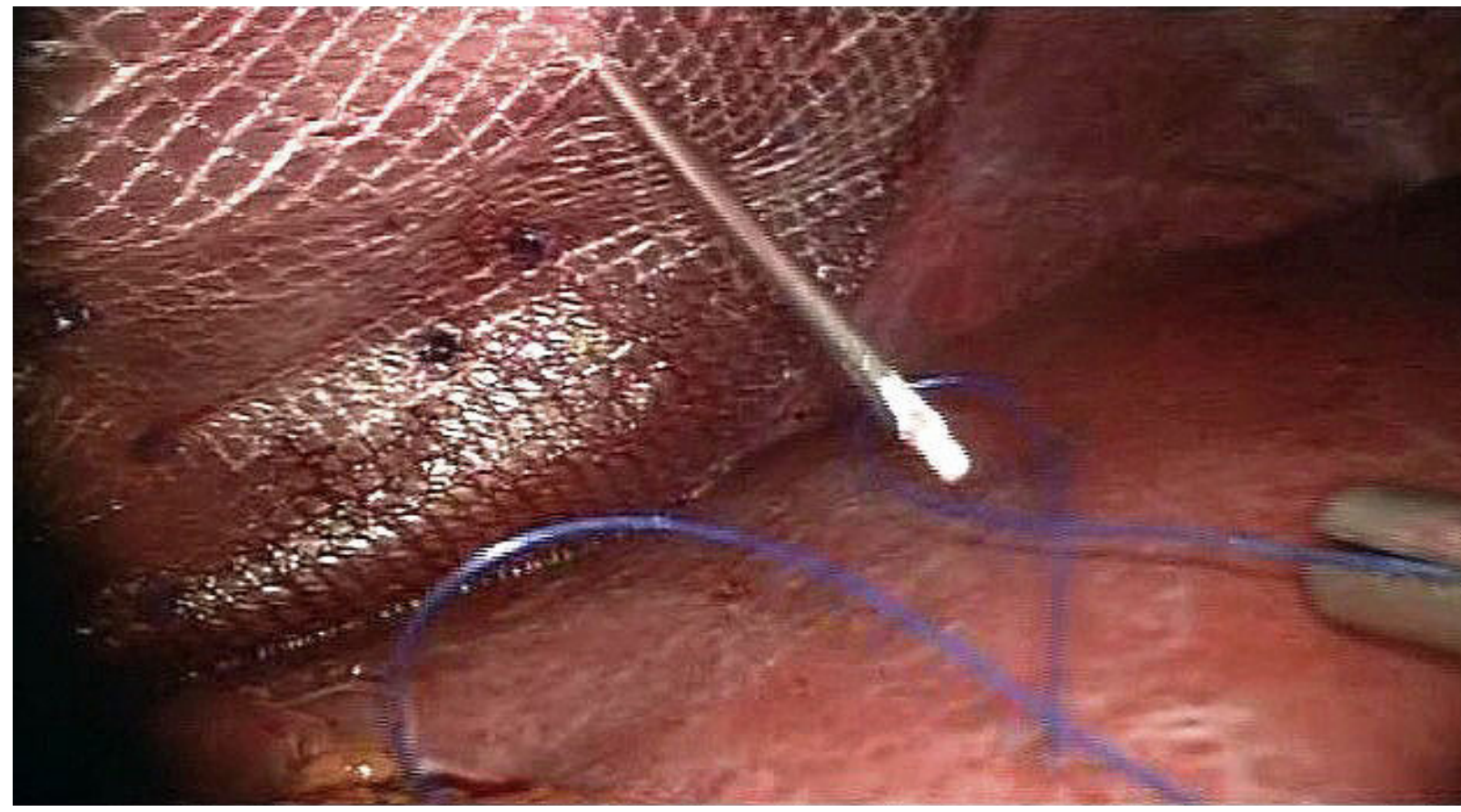

Resim 3. Serbest prolen ile fiksasyon dikişleri.

İpler buraya bir defada konularak gereksiz alet giriş ve çıkışı önlendi. Sütür tutucu ile önce cilt, daha sonra sirasiyla, eski operasyona ait yerinden ayrilmıș yama, sağlam faysa ve yeni yama delindi. İplik tek ucu tutularak karın dışına çıkarıldı ve işlem tekrar edilerek diğer uç ta karın dışına alındı ve cilt altında kalacak şekilde tespit dikişleri bağlandı (Re$\operatorname{sim} 3$ ). Tespit sütürleri 3'er cm arayla atıldı.Güvenli yama sabitliği sağlayacak kadar sütür atılmasını takiben ameliyat sonlandırıldı. Ameliyat sonrası dönemi sorunsuz seyreden hasta, 3. gününde taburcu edildi.

\section{TARTIŞMA}

Karın ameliyatları sonrası, \%10 oranda kesi fitığ 1 gelişmektedir (1). Kesi fitıklarında primer dikiş ile tamirden sonra fitık tekrarlama oranı her girișim sonrası artmaktadır. Prostetik yama kullanımının bu riski azalttığının (\%32-\%63) ortaya konmasindan bu yana, yamalar fitik cerrahisinde standart olarak kullanılmaya başlanmıştır (7). 1990'ların başında karın duvarı fitıklarında, laparoskopik intraperitoneal yama kullanımı tarif edilmiștir (8). Laparoskopik yama sabitlemede ana prensipler, organların yamanın üzerine fitıklaşmasının engellenmesi, yamanın kendi üzerine katlanmasının önlenmesi ve yamanın kenarlarının fitık halkasından belirli ve eş uzaklıklara sabitlemektir. Fitık halkasindan en az $4 \mathrm{~cm}$ (obez hastalarda en az $5 \mathrm{~cm}$ ) uzaklık hesaplanarak yamanın ölçüleri alınmalıdır (9). Bu uzaklık bizim olgumuzda olduğu gibi palpasyonla karındaki izdüşümü çizilerek hesaplanabilir ya da steril cetvel kullanılarak laparoskopi yardımıyla fitık halkasının boyutları ölçülebilir.

Tanımlandığı tarihten itibaren yamanın karın duvarına sabitlenmesi zımba atıcilar ve transfasyal dikişler ile yapılmıştır. Her iki yöntem de yaygın olarak kullanılmasına karşın fitık cerrahisinde hangisinin ideal olduğu halen tartışmalıdır. $\mathrm{Bu}$ konu hakkında yapılan tek prospektif randomize çalışmada transfasyal dikişin ameliyat sonrası ilk altı haftada daha ağrılı olduğu izlenilmiş fakat yama katlanmasının zimba atıcılara kıyasla daha az olduğu gösterilmiştir (10). Ağrının etiyolojisinin yamaya bağlı peritonit ve fiksasyon materyalleri olduğu düşünülmektedir fakat ameliyat sonras1 kronik ağrının asıl nedeni açıklanamamıştır (9).

Bazı çalışmalarda nöral hasara bağlı kronik ağrı oluştuğu düşünülmüş ve sınırlı hasta grubunda fiksasyon materyalleri çıkarılıp ağrının gerilediği görülmüştür (11). Bazı yazarlar da zımbaların peritonu sıkıştırdığı için kronik ağrının oluştuğunu savunmuşlardır (12). Bu sebeplerle üretilen, emilebilir zımbaların, kronik ağrıda anlamlı olarak avantajlı olduğu görülmüş ve yaygın olarak kullanılmaya başlanmıştır. Ayrıca literatürde, yama sabitlemede yapıştırıcı kullanımının tartışıldı ğ birkaç çalışma mevcuttur fakat henüz uzun dönem hiçbir sonuç yayınlanmamıştır (13-15).

Laparoskopik fitık cerrahisi zımba atıcılar sayesinde oldukça kolaylaşmıştır. Uygulamada zımba atıcı ile karın içinden ve elle ters istikamette karın dişından uygulanan baskı, yamayı sıkıştırıp güvenle dokuya zımbalama imkanı vermektedir. Fakat bizim vakamızda olduğu gibi subkostal bölgede bu manüplasyon kotlar nedeni ile mümkün olmamaktadır.

Karın dışından el ile manüplasyonu mümkün olmayan alanlar için açılı sabitleyiciler üretilmiştir. Yapılan deneysel bir çalışmada standart zımba atıc1 ve açılı zımba atıcı karşılaştırılmıştır, açılı aletin yamayı karın duvarına daha güçlü tespit ettiği gösterilmiştir. Fakat artiküle aletlerle henüz yeterli klinik çalışma yayınlanmamıştır (16). 
Bu bölge için bir diğer önemli sorun ise interkostal sinir hasarı, olası periost reaksiyonu ve beraberlerinde getirdikleri kronik ağrı riskidir. Bu bölgede transfasyal dikişler oldukça faydalıdır ve birkaç farklı teknik ile atılabilir.

Bizim tarif ettiğimiz yöntemde $15 \mathrm{~cm}$ uzunluğunda serbest prolen iplikler karın içine tek seferde alınır ve karaciğer üstüne bırakılır. Sütür tutucu yardımıyla cilt, cilt altı dokular ve yama delinerek ipliğin bir ucu karın dışına alınır ve işlem tekrar edilerek diğer uç ta karın dışına çıkarılarak tespit dikişi oluşturulur.

\section{SONUÇ}

Tekrar eden karın duvarı kesi fitıklarında laparoskopik fitık tamiri güvenle uygulanmaktadır. Yama sabitlemede zımba atıcılar kullanımı basit ve ameliyat süresini kısaltan aletlerdir. Fakat açısı zor ve kronik ağrı riski taşıyan bölgelerde tercih edilmemelidir. Sütür tutucular yardımı ile laparoskopik transfasyal yama sabitleme, torakoabdominal bölge fitıklarında uygulanabilen ucuz, güvenli bir alternatif yöntemdir.

\section{KAYNAKLAR}

1. Mudge M, Hughes LE. Incisional hernia: a 10-year prospective study of incidence and attitudes. Br J Surg 1985;72:70-1.

2. Hawn MT, Snyder CW, Graham LA, Gray SH, Finan KR, Vick CC (2010) Long-term follow-up of technical outcomes for incisional hernia repair. J Am Coll Surg 210:648-657

3. Beldi $G$, Ipaktchi R, Wagner M, Gloor B, Candinas D (2006) Laparoscopic ventral hernia repair is safe and cost effective. Surg Endosc 20:92-95

4. Bingener J, Buck L, Richards M, Michalek J, Schwesinger W, Sirinek $K$ (2007) Long-term outcomes in laparoscopic vs open ventral hernia repair. Arch Surg 142:562-567

5. Chelala E, Thoma M, Tatete B, Lemye AC, Dessily M, Alle JL (2007) The suturing concept for laparoscopic mesh fixation in ventral and incisional hernia repair: mid-term analysis of 400 cases. Surg Endosc 21:391-395

6. Heniford BT, Park A, Ramshaw BJ, Voeller G (2003) Laparoscopic repair of ventral hernias: nine years' experience with 850 consecutive hernias. Ann Surg 238:391-399; discussion 399-400

7. Burger JWA, Luijendijk RW, Hop WCJ, et al. Long-term followup of a randomized controlled trial of suture versus mesh repairof incisional hernia. Ann Surg 2004;240:578-83.

8. LeBlanc KA, Booth WV. Laparoscopic repair of incisional abdominal hernias using expanded polytetrafluoroethylene: preliminary findings. Surg Laparosc Endosc 1993;3:39—41.

9. P.-E. Moreau, N. Helmy, C. Vons. Laparoscopic treatment of incisional hernia. State of the art in 2012. Journal of Visceral Surgery (2012) 149, e $40-e 48$

10. Beldi G, Wagner M, Bruegger LE, Kurmann A, Candinas D. Mesh shrinkage and pain in laparoscopic ventral hernia repair: a randomized clinical trial comparing suture versus tack mesh fixation. Surg Endosc. 2011 Mar;25(3):749-55. doi: 10.1007/s00464-010-1246-0. Epub 2010 Jul 23.

11. Perrone JM, Soper NJ, Eagon JC, et al. Perioperative outcomes and complications of laparoscopic ventral hernia repair. Surgery $2005 ; 138: 708-15$

12. Sauerland S, Walgenbach M, Habermalz B, Seiler CM, Miserez M. Laparoscopic versus open surgical techniques for ventral or incisional hernia repair. Cochrane Database Syst Rev 2011;(3) [CD007781].

13. Dilege E, Deveci $U$, Erbil $Y$, et al. $N$-butyl cyanoacrylate versus conventional suturing for fixation of meshes in an incisional hernia model. J Invest Surg 2010;23:262-6

14. Morales-Conde S, Barranco A, Socas M, et al. Systematic review of the use of fibrin sealant in abdominal-wall repair surgery. Hernia $2011 ; 15: 361-9$.

15. Eriksen JR, Bisgaard T, Assaadzadeh S, Jorgensen LN, Rosenberg $J$. Randomized clinical trial of fibrin sealant versus titanium tacks for mesh fixation in laparoscopic umbilical hernia repair. Br J Surg 2011;98:1537-45

16. Elazary R, Kedar A, Abu-Gazala M, Mintz Y. Comparing laparoscopic mesh fixation strength between articulated and non articulated tack devices. Minim Invasive Ther Allied Technol. 2013 Feb 4. 